\title{
Relationship of Urinary cGMP Excretion with Aging and Menopausal Status in a General Population
}

\author{
Renzhe Cui ${ }^{1}$, Hiroyasu Iso ${ }^{1}$, Kazumasa Yamagishi ${ }^{2}$, Tetsuya Ohira ${ }^{1,4}$, Takeshi Tanigawa ${ }^{3}$, Akihiko Kitamura ${ }^{4}$, \\ Masahiko Kiyama ${ }^{4}$, Hironori Imano ${ }^{1,4}$, Masamitsu Konishi ${ }^{4}$, and Takashi Shimamoto ${ }^{4}$ \\ ${ }^{1}$ Public Health, Department of Social and Environmental Medicine, Osaka University, Graduate School of Medicine, Osaka, Japan \\ ${ }^{2}$ Department of Public Health Medicine, Graduate School of Comprehensive Human Sciences and Institute of Community \\ Medicine, University of Tsukuba, Tsukuba, Japan \\ ${ }^{3}$ Department of Public Health, Doctoral Program in Social Medicine, Graduate School of Medicine, Ehime University, Ehime, Japan \\ ${ }^{4}$ The Osaka Medical Center for Health Science and Promotion, Osaka, Japan
}

\begin{abstract}
Aim: Aging and postmenopausal women are associated with increased risks of cardiovascular disease; however, epidemiological evidence concerning the relationship of aging and the menopause with vascular biological activity is limited.

Methods: We investigated the relationship of aging and the menopause with urinary excretion of cyclic guanosine 3',5' monophosphate (cGMP) in 1,541 Japanese men and women aged 40 to 79 years. The 24-hour urinary excretion of cGMP was measured with a ${ }^{125}$ I-labeled cGMP radioimmunoassay and was adjusted for urinary creatinine excretion ( $\mathrm{nmol} / \mathrm{mmol}$ creatinine).

Results: Aging was positively associated with urinary excretion of cGMP for both sexes. Postmenopausal women excreted significantly less urinary cGMP than premenopausal women after adjustment for age and other cardiovascular risk factors: $48.3 \pm 0.04 \mathrm{nmol} / \mathrm{mmol}$ vs. $61.5 \pm 0.07 \mathrm{nmol} / \mathrm{mmol}$, $p=0.006$.

Conclusions: Our data suggest that cGMP-related vasodilatation is impaired in postmenopausal women.
\end{abstract}

J Atheroscler Thromb, 2009; 16:457-462.

Key words; cGMP, Postmenopausal, Cross-sectional studies, Epidemiology

\section{Introduction}

The cyclic guanosine 3',5' monophosphate (cGMP) is the second messenger not only of nitric oxide (NO) but also of natriuretic peptides ${ }^{1-3)}$. NO plays an important role in the regulation of vascular tone, thrombocyte activation, neurotransmission, and host defense ${ }^{2)}$, and the biological activity of $\mathrm{NO}$ is impaired in atherosclerotic vascular diseases. Levels of natriuretic peptides are correlated with vascular resistance, blood volume, and heart failure ${ }^{1,3)}$. Previous studies have

Address for correspondence: Hiroyasu Iso, Public Health, Department of Social and Environmental Medicine, Osaka University Graduate School of Medicine, 2-2 Yamadaoka,

Suita-shi, Osaka 565-0871, Japan

E-mail: iso@pbhel.med.osaka-u.ac.jp

Received: August 2, 2008

Accepted for publication: February 19, 2009 reported that the levels of cGMP were reduced in rabbits with experimentally induced atherosclerosis ${ }^{4)}$ and in patients with peripheral arterial occlusive disease ${ }^{5)}$. We reported recently that urinary cGMP excretion was reduced in patients with metabolic syndrome, and was lower in association with high serum total cholesterol levels in the general population ${ }^{6,7)}$.

It is well known that postmenopausal aging women are associated with increased risks of cardiovascular disease ${ }^{8,9)}$. Previous clinical studies indicate that aging is associated with reduced acetylcholineinduced vasodilation ${ }^{10)}$, inversely associated with flowmediated dilatation ${ }^{11)}$, and inversely associated with increased L-arginine-induced cGMP levels ${ }^{12}$. Postmenopausal women show impaired vascular endothelial function ${ }^{13)}$, and this impairment can be effectively treated with hormone replacement therapy ${ }^{14)}$ and cholesterol-lowering therapy ${ }^{15)}$. These findings suggest 
that endothelial dysfunction may contribute to the development of atherosclerosis.

To date, however, few epidemiological studies have examined the relationship between aging and a postmenopausal status on the one hand and vascular biological activity. The purpose of this study was to examine the association of age and a postmenopausal status with urinary excretion of cGMP in a large population-based sample numbering around 1,500.

\section{Methods}

\section{Study Subjects}

Six annual cardiovascular risk surveys from 1997 to 2002 were performed in 788 men and 753 women aged 40-79 years, who also undersent 24-hour urine collection. These surveys have been conducted in two farming communities, Ikawa in northeast Japan (census population aged 40-79 in 1995: $n=3,306)$ since 1963 and in Kyowa in central Japan since $1981(n=$ 8 ,286). The participation rates in the 1997-2002 survey were $58 \%$ in Ikawa and $53 \%$ in Kyowa. The Ethics Committee of the University of Tsukuba approved the study.

\section{Subjects and Measurement of Cardiovascular Risk Factors}

Cardiovascular risk factors were measured in all 1997-2002 surveys. Height in stocking feet and weight in light clothing were measured. Body mass index was calculated as weight $(\mathrm{kg})$ divided by the square of the height in meters $\left(\mathrm{m}^{2}\right)$. Seated systolic and diastolic blood pressures were measured by trained observers using standard mercury sphygmomanometers on the right arm of participants who had rested for at least $5 \mathrm{~min}^{16)}$. Protocols for measuring serum lipids and glucose levels, and assessment of smoking and drinking habits, medication use for hypertension and diabetes mellitus, and menopausal status by interview, establishing a history of stroke and coronary heart disease were carried out according to standardized criteria, and the quality-control procedures have been reported previously ${ }^{17}{ }^{18)}$. Hypertension was defined as systolic blood pressure $\geq 140 \mathrm{mmHg}$, diastolic blood pressure $\geq 90 \mathrm{mmHg}$, and/or the use of antihypertensive medication. Diabetes mellitus was defined as a fasting glucose level $\geq 7.0 \mathrm{mmol} / \mathrm{L}$, nonfasting glucose level $\geq 11.1 \mathrm{mmol} / \mathrm{L}$, and/or use of medication for diabetes. Cardiovascular disease was defined as a history of stroke or coronary heart disease. Menopause was defined as non-menstruation for 6 months or more. Persons who smoked $\geq 1$ cigarette per day were defined as current smokers. An inter- viewer assessed the normal weekly intake of ethanol in units of "go", a traditional Japanese unit of volume corresponding to $23 \mathrm{~g}$ ethanol, and converted to grams of ethanol per day.

\section{Assay for Biochemical Variables}

Non-fasting venous blood was drawn from seated participants into a plain, siliconized glass tube and serum was separated within $30 \mathrm{~min}$. The serum sample was stored at $-70^{\circ} \mathrm{C}$ until measurement. Serum total cholesterol, HDL-cholesterol, and triglycerides were measured by the Liebermann-Burchard direct method using Autoanalyzer II (Technicon, Tarrytown, NY) or using enzymatic methods and an automatic analyzer (model 7250; Hitachi Medical Corp., Hitachi, Japan) at the Osaka Medical Center for Health Science and Promotion, an international member of the US National Cholesterol Reference Method Laboratory Network (CRMLN) ${ }^{19)}$, Serum glucose was measured by the cupric-neocuproine method or hexokinase method. Serum C-reactive protein (CRP) levels were measured with a latex agglutination immunoassay (Automatic Analyzer Model 7600-210; Hitachi). The inter-assay coefficient of variation was $2.5 \%$ for serum CRP.

Twenty-four-hour urine samples were collected using 3-liter plastic bottles. Permission for the 24-h urine collection was obtained after full explanation of its purpose and procedure. Participants were questioned carefully to ascertain the completeness of 24-h urine collection. After the total urinary volume was measured, urine aliquots for laboratory analysis were prepared and frozen at $-80^{\circ} \mathrm{C}$ until analysis. Urinary creatinine concentration was analyzed using the Jaffe alkaline picrate method with a spectrophotometer (Hitachi Autoanalyzer model 7150). Urine samplings that were incomplete based on the records and/or had creatinine excretion $<3.5$ or $\geq 22.1 \mathrm{mmol} / \mathrm{d}$ were excluded from the analysis. Urinary cGMP concentrations were measured with a ${ }^{125}$ I-labeled cGMP radioimmunoassay kit (cGMP assay RPA 525; Amersham, Buckinghamshire, UK) ${ }^{6,7)}$, divided by urinary creatinine concentration and expressed in $\mathrm{nmol} / \mathrm{mmol}$ of creatinine to reduce variability due to differences in renal function ${ }^{5}$. The inter-assay coefficient of variation was $3.2 \%$ for cGMP.

\section{Statistical Analysis}

Because the values of urinary cGMP, serum CRP and triglycerides were skewed, they were log-transformed for the analysis, and presented as geometric means. We calculated the sex-specific age-adjusted mean values and the proportion of selected cardiovas- 
Table 1. Sex-specific age-adjusted mean values (standard errors) and proportions of cardiovascular risk factors for Japanese aged 40-79 years

\begin{tabular}{lccc}
\hline & Men & Women & $p$ for difference \\
\hline Number & 788 & 753 & $<0.001$ \\
Age (years) & $61.0(0.3)$ & $56.5(0.3)$ & 0.12 \\
Body mass index (kg/m²) & $23.2(0.2)$ & $23.5(0.2)$ & 0.43 \\
Systolic blood pressure (mmHg) & $136.1(0.6)$ & $135.4(0.6)$ & $<0.001$ \\
Diastolic blood pressure (mmHg) & $82.3(0.4)$ & $80.2(0.4)$ & $<0.001$ \\
Serum CRP (mg/L) & $0.37(0.19)$ & $0.28(0.14)$ & $<0.001$ \\
Total cholesterol (mg/dL) & $197.9(1.2)$ & $212.6(1.2)$ & $<0.001$ \\
HDL-cholesterol (mg/dL) & $55.1(0.5)$ & $61.5(0.5)$ & $<0.001$ \\
Triglycerides (mg/dL) & $141.6(3.1)$ & $113.2(3.1)$ & $<0.001$ \\
Ethanol intake (g/day) & $26.4(0.7)$ & $1.1(0.7)$ & $<0.001$ \\
Current smoker (\%) & 42.4 & 1.6 & 0.27 \\
Antihypertensive medication use (\%) & 22.7 & 25 & 0.02 \\
Diabetes mellitus (\%) & 8.9 & 5.7 & 0.12 \\
History of cardiovascular disease (\%) & 3.2 & 1.9 & - \\
Post-menopause (\%) & - & 69.7 & \\
\hline
\end{tabular}

Data are the mean \pm SE or percentages. Geometric mean \pm SE is used for serum CRP and triglycerides.

cular risk characteristics. Differences in the mean values of urinary cGMP excretion levels were determined by comparative analysis of data for sex and menopause status groups by analysis of covariance. Multiple linear regression was used to estimate predicted changes in urinary cGMP excretion associated with changes in selected cardiovascular risk factors. Potential confounding or interacting factors, namely, systolic blood pressure $(\mathrm{mmHg})$, total and HDL-cholesterol levels $(\mathrm{mg} / \mathrm{dL})$, triglycerides $(\mathrm{mg} / \mathrm{dL})$, serum CRP $(\mathrm{mg} / \mathrm{L})$, current smoker (yes), ethanol intake (g/day), antihypertensive medication use (yes), diabetes mellitus (yes), history of cardiovascular disease (yes), time since last meal $(<2,2,3-7$ and $\geq 8 \mathrm{~h})$ and community were all taken into account. The SAS statistical package version 9.1 (SAS Institute Inc., Cary, NC) was used for all analyses. All $p$ values for statistical tests were twotailed, and values $<0.05$ were regarded as significant.

\section{Results}

We examined the mean values and proportions of major cardiovascular risk factors between subjects with and without 24-h urine collection samples in this study and found no differences between the two groups, for example, the respective mean values of body mass index were 23.7 and $23.7 \mathrm{~kg} / \mathrm{m}^{2}$ for men, and 24.1 and $23.9 \mathrm{~kg} / \mathrm{m}^{2}$ for women. The respective percentages of hypertension (systolic blood pressure $\geq 140$, diastolic blood pressure $\geq 90 \mathrm{mmHg}$ and/or antihypertensive medication use) were $40.4 \%$ vs.
$44.6 \%$ for men, and 29.4 vs. $31.3 \%$ for women; those of current smokers were $45.0 \%$ vs. $45.6 \%$ for men, and $3.2 \%$ vs. $1.6 \%$ for women.

Table 1 shows sex-specific age-adjusted mean values \pm standard errors (SE) and percentages of selected cardiovascular risk factors. The mean values of age, diastolic blood pressure, serum CRP, triglycerides, alcohol intake, and of current smokers and diabetes were lower for women, while the mean values of total and HDL-cholesterol were higher for women than for men.

Table 2 shows the sex-specific mean values $( \pm S E)$ of urinary cGMP excretion by age group. Women excreted more urinary cGMP than men $(57.8 \pm 0.03$ $\mathrm{nmol} / \mathrm{mmol}$ for women, $42.9 \pm 0.03 \mathrm{nmol} / \mathrm{mmol}$ for men, $p<0.001$ ), while women aged 40-49 and 60-69 years showed significantly higher excretion of urinary cGMP than men in the same age group.

The mean values of urinary cGMP excretion by age group and menopausal status are shown in Table 3. Postmenopausal women excreted less urinary cGMP than premenopausal women (multivariable adjusted $\mathrm{cGMP}=48.3 \pm 0.03 \mathrm{nmol} / \mathrm{mmol}$ for postmenopausal women, $61.5 \pm 0.07 \mathrm{nmol} / \mathrm{mmol}$ for premenopausal women; $p=0.006$ ).

Postmenopausal women showed lower excretion of urinary cGMP than premenopausal women in the same age group. The difference in urinary cGMP excretion levels between postmenopausal and premenopausal women was statistically significant for the 50-59 and 60-69 age groups.

We also examined sex-specific predicted changes 
Table 2. Sex-specific mean values (standard errors) for urinary cGMP excretion ( $\mathrm{nmol} / \mathrm{mmol}$ of creatinine) by age group

\begin{tabular}{|c|c|c|c|c|c|}
\hline & \multicolumn{5}{|c|}{ Age group, years } \\
\hline \multicolumn{6}{|l|}{ Number } \\
\hline Men & 120 & 156 & 378 & 134 & 788 \\
\hline Women & 179 & 274 & 265 & 35 & 753 \\
\hline \multicolumn{6}{|l|}{ Non-adjusted cGMP } \\
\hline$p$ for difference & $<0.001$ & 0.79 & 0.94 & 0.86 & 0.004 \\
\hline \multicolumn{6}{|c|}{ Multivariable-adjusted cGMP } \\
\hline Men & $31.3(0.09)$ & $44.3(0.08)$ & $44.2(0.05)$ & $59.0(0.06)$ & $42.9(0.03)$ \\
\hline Women & $63.4(0.07)$ & $54.5(0.06)$ & $55.7(0.06)$ & $72.2(0.15)$ & $57.8(0.03)$ \\
\hline$p$ for difference & $<0.001$ & 0.07 & 0.005 & 0.20 & $<0.001$ \\
\hline
\end{tabular}

Geometric mean \pm S.E. is shown for urinary cGMP excretion. Multivariable-adjusted for body mass index $\left(\mathrm{kg} / \mathrm{m}^{2}\right)$, systolic blood pressure $(\mathrm{mmHg})$, total and HDL-cholesterol (mg/dL), triglyceride $(\mathrm{mg} / \mathrm{dL})$, serum CRP levels $(\mathrm{mg} / \mathrm{L})$, ethanol intake (g/day), current smokers (yes), diabetes mellitus (yes), antihypertensive medication use (yes), history of cardiovascular disease (yes), time since last meal (h), and community.

Table 3. Mean values (standard errors) of urinary cGMP excretion ( $\mathrm{nmol} / \mathrm{mmol}$ of creatinine) by age group and menopausal status for women

\begin{tabular}{|c|c|c|c|c|c|}
\hline & \multicolumn{5}{|c|}{ Age group, years } \\
\hline Premenopause & 158 & 60 & 10 & 0 & 228 \\
\hline Postmenopause & 21 & 214 & 255 & 35 & 525 \\
\hline \multicolumn{6}{|l|}{ Non-adjusted cGMP } \\
\hline Postmenopause & $44.5(0.19)$ & $48.1(0.05)$ & $47.5(0.05)$ & $62.2(0.14)$ & $46.9(0.04)$ \\
\hline$p$ for difference & 0.07 & 0.02 & 0.002 & - & $<0.001$ \\
\hline \multicolumn{6}{|c|}{ Multivariable-adjusted cGMP } \\
\hline Premenopause & $61.2(0.06)$ & $61.2(0.10)$ & $113.5(0.33)$ & - & $61.5(0.07)$ \\
\hline Postmenopause & $46.0(0.20)$ & $48.4(0.05)$ & $47.2(0.05)$ & $62.8(0.14)$ & $48.3(0.04)$ \\
\hline
\end{tabular}

Geometric mean \pm S.E is shown for urinary cGMP excretion. Variables of multivariable adjustment are as in the footnote of Table 2.

in urinary excretion of cGMP levels associated with increments of cardiovascular risk factors (Table 4). Aging was positively associated with urinary cGMP for both sexes. Current smoking was positively associated with urinary cGMP for men. Total cholesterol and menopausal status were inversely associated with urinary cGMP for women.

\section{Discussion}

In our present study, aging was positively associated with urinary excretion of cGMP for both men and women. Our finding is consistent with the results of an recent epidemiological study reporting that serum NOx concentrations were positively associated with aging among 3505 men and women aged $\geq 20$ years ${ }^{20}$. An experimental study reported that $\mathrm{NOx}$ and cGMP levels were higher and the activity of eNOS was lower accompanied by higher activity of iNOS in aging rats than in young rats $^{21,22}$. The amount of $\mathrm{NO}$ generated was small by the activation of eNOS for seconds or minutes, while the amount of $\mathrm{NO}$ was large by the activation of iNOS for delayed and prolonged periods for days ${ }^{2,23)}$. Thus, this mechanism may explain the positive association between aging and cGMP in the present study. An other possi- 
Table 4. Multivariable-adjusted predicted change in cGMP levels associated with changes in cardiovascular risk factors among Japanese aged $40-79$ years

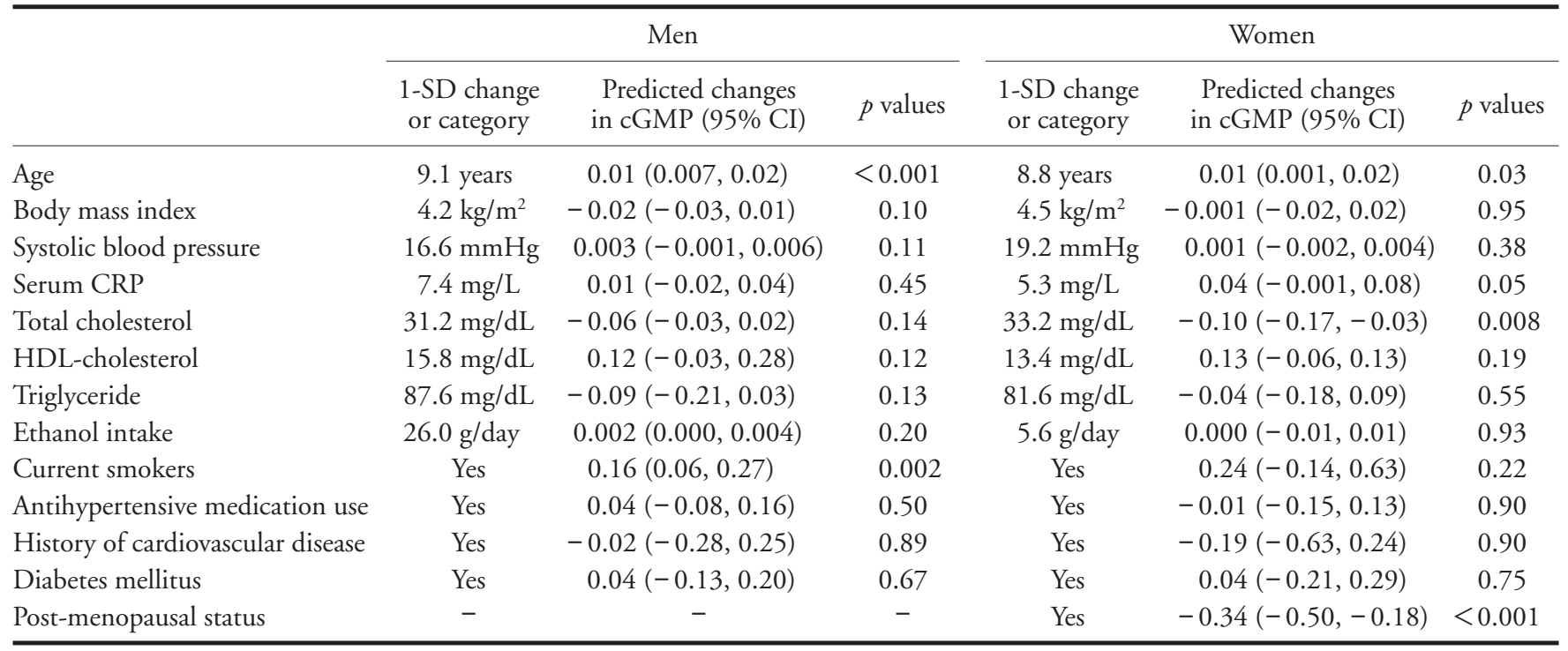

Variables of multivariable adjustment are as in the footnote of Table 2, with age (year) and menopause status (yes) for women

ble explanation is that cGMP is the second messenger not only of $\mathrm{NO}$ but also of natriuretic peptides ${ }^{1,2)}$, which were positively associated with aging ${ }^{24-26)}$ Thus, increased cGMP levels associated with aging were probably due to increased levels of both iNOS and natriuretic peptides.

Postmenopausal women had lower urinary cGMP excretion than premenopausal women, regardless of age. This finding suggests that cGMP-related vasodilatation is impaired in women after menopause, and our result is in agreement with the results of a previous clinical study, in which postmenopausal women proved to have impaired vascular endothelial function, that is, a reduced effect of acetylcholine on vascular resistance ${ }^{13)}$. A plausible causative mechanism for this finding is that postmenopausal women feature endogenous estrogen depletion and elevated serum total or LDL-cholesterol levels ${ }^{27}$. We previously reported that the levels of urinary cGMP excretion were inversely associated with serum total cholesterol levels ${ }^{7)}$.

The strength of the present study is that it examined the associations of aging and menopause status with urinary cGMP excretion in a large populationbased sample. The potential limitation is that we could not identify a causal relationship due to the cross-sectional design; however, a previous clinical study supports the notion of a causal relationship between menopause and endothelial dysfunction ${ }^{28)}$. In that study, women with premature ovarian failure had endothelial dysfunction, but hormone replacement therapy restored endothelial function within 6 months of treatment.

In conclusion, our epidemiological study provides evidence that urinary cGMP excretion levels of women after menopause are lower than those of premenopausal women, regardless of age. Our data suggest that cGMP-related vasodilatation is impaired in women after menopause.

\section{Acknowledgment}

This study was supported by a Grant-in-Aid for exploratory research from the Japan Society for the Promotion of Science, Japan (No. 11877069, 19992000 and, No. 18659179 in 2006-2007).

\section{References}

1) Booz GW: Putting the brakes on cardiac hypertrophy: exploiting the NO-cGMP counter-regulatory system. Hypertension, 2005; 45:341-346

2) Moncada $S$, Higgs A: The L-arginine-nitric oxide pathway. N Engl J Med, 1993; 329:2002-2012

3) Wright SP, Prickett TC, Doughty RN, Frampton C, Gamble GD, Yandle TG, et al: Amino-terminal pro-Ctype natriuretic peptide in heart failure. Hypertension, 2004; 43:94-100

4) Szilvássy Z, Csont T, Páli T, Droy-Lefaix MT, Ferdinandy P: Nitric oxide, peroxynitrite and cGMP in atherosclerosis-induced hypertension in rabbits: beneficial effects of cicletanine. J Vasc Res, 2001; 38:39-46 
5) Böger RH, Bode-Böger SM, Thiele W, Junker W, Alexander K, Frölich JC: Biochemical evidence for impaired nitric oxide synthesis in patients with peripheral arterial occlusive disease. Circulation, 1997; 95:2068-2074

6) Cui R, Iso H, Pi J, Kumagai Y, Yamagishi K, Tanigawa T, Shimamoto T: Metabolic syndrome and urinary cGMP excretion in a general population. Atherosclerosis, 2007; $190: 423-428$

7) Cui R, Iso H, Pi J, Kumagai Y, Yamagishi K, Tanigawa T, Shimamoto T: Relationship between urinary cGMP excretion and serum total cholesterol levels in a general population. Atherosclerosis, 2005; 179:379-386

8) Gordon T, Kannel WB, Hjortland MC, McNamara PM: Menopause and coronary heart disease. The Framingham Study. Ann Intern Med, 1978; 89:157-161

9) Colditz GA, Willett WC, Stampfer MJ, Rosner B, Speizer FE, Hennekens $\mathrm{CH}$ : Menopause and the risk of coronary heart disease in women. N Engl J Med, 1987; 316:11051110

10) Taddei S, Virdis A, Mattei P, Ghiadoni L, Gennari A, Fasolo CB, Sudano I, Solvetti A: Aging and endothelial function in normotensive subjects and patients with essential hypertension. Circulation, 1995; 91:1981-1987

11) Kirma C, Akcakoyun M, Esen AM, Barutcu I, Karakaya O, Saglam M, Kagin R, Turkmen M, Boztosur B, Izgi A, Senmez K: Relationship between endothelial function and coronary risk factors in patients with stable coronary artery disease. Circ J, 2007; 71:698-702

12) Higashi Y, Oshima T, Ozono R, Matsuura H, Kajiyama G: Aging and severity of hypertension attenuate endothelium-dependent renal vascular relaxation in humans. Hypertension, 1997; 30:252-258

13) Taddei S, Virdis A, Ghiadoni L, Mattei P, Sudano I, Bernini G, Pinto S, Salvetti A: Menopause is associated with endothelial dysfunction in women. Hypertension, 1996; 28:576-582

14) Herrington DM, Espeland MA, Crouse JR 3rd, Robertson J, Riley WA, McBurnie MA, Burke GL: Estrogen replacement and brachial artery flow-mediated vasodilation in older women. Arterioscler Thromb Vasc Biol, 2001; 21:1955-1961

15) Yoshihisa $A$, Iwai-Takano $M$, Yaoita $H$, Watanabe $T$, Maruyama Y: Difference in early effects of statin therapy on coronary and forearm flow reserve in postmenopausal hypercholesterolemic women. Circ J, 2007; 71:954-961

16) Kirkendall WM, Feinleib M, Freis ED, Mark AL: Recommendations for human blood pressure determination by sphygmomanometers. Subcommittee of the AHA Postgraduate Education Committee. Circulation, 1980; $62: 1146 \mathrm{~A}-1155 \mathrm{~A}$

17) Shimamoto $T$, Komachi $Y$, Inada $H$, Doi $M$, Iso $H$, Sato $S$, Kitamura A, Iida M, Konishi M, Nakanishi N: Trends for coronary heart disease and stroke and their risk factors in Japan. Circulation, 1989; 79:503-515

18) Shimamoto $T$, Iso $H$, Tanigawa $T$, Sankai $T$, Ohira $T$, Okawa $\mathrm{Y}$, et al: Stroke, ischemic heart disease and their risk factors in Kyowa town, Ibaraki, Japan. Cardioangiology, 2000; 48:127-133 (in Japanese)

19) Nakamura $M$, Sato $S$, Shimamoto T: Improvement in Japanese clinical laboratory measurements of total cholesterol and HDL-cholesterol by the US Cholesterol Reference Method Laboratory Network. J Atheroscler Thromb, 2003; 10:145-153

20) Ghasemi A, Zahedi Asl S, Mehrabi Y, Saadat N, Azizi F: Serum nitric oxide metabolite levels in a general healthy population: relation to sex and age. Life Sci, 2008; 83:326331

21) Cernadas MR, Sánchez de Miguel L, García-Durán M, González-Fernández F, Millás I, Montón M, Radrigo J, Rico L, Fernández P, de Frutos T, Rodríguez-Feo JA, Guerra J, Caramelo C, Casada S, López-Farré: Expression of constitutive and inducible nitric oxide synthases in the vascular wall of young and aging rats. Circ Res, 1998; 83:279-286

22) Chou TC, Yen MH, Li CY, Ding YA: Alterations of nitric oxide synthase expression with aging and hypertension in rats. Hypertension, 1998; 31:643-648

23) Nathan C: Nitric oxide as a secretory product of mammalian cells. FASEB J, 1992; 6:3051-3064

24) Kato J, Kitamura K, Uemura T, Kuwasako K, Kita T, Kangawa K, Eto T: Plasma levels of adrenomedullin and atrial and brain natriuretic peptides in the general population: their relations to age and pulse pressure. Hypertens Res, 2002; 25:887-892

25) Redfield MM, Rodeheffer RJ, Jacobsen SJ, Mahoney DW, Bailey KR, Burnett JC Jr: Plasma brain natriuretic peptide concentration: impact of age and gender. J Am Coll Cardiol, 2002; 40:976-982

26) Kaneki H, Kurokawa M, Ide H: The receptor attributable to C-type natriuretic peptide-induced differentiation of osteoblasts is switched from type B- to type C-natriuretic peptide receptor with aging. J Cell Biochem, 2008; 103:753-764

27) Walsh BW, Schiff I, Rosner B, Greenberg L, Ravnikar V, Sacks F: Effects of postmenopausal estrogen replacement on the concentrations and metabolism of plasma lipoproteins. N Engl J Med, 1991; 325:1196-1204

28) Kalantaridou SN, Naka KK, Papanikolaou E, Kazakos N, Kravariti M, Calis KA, Paraskevaidis EA, Sideris DA, Tsatsoulis A, Chrousos GP, Michalis LA: Impaired endothelial function in young women with premature ovarian failure: normalization with hormone therapy. J Clin Endocrinol Metab, 2004; 89:3907-3913 